NBER WORKING PAPER SERIES

AS ASSESSMENT OF THE BENEFITS

OF AIR POLLUTION CONTROL:

THE CASE OF INFANT DEATH

Theodore J. Joyce

Michael Grossman

Fred Go Idman

Working Paper No. 1928

NATIONAL BUREAU OF ECONOMIC RESEARCH

1050 Massachusetts Avenue

Cambridge, MA 02138

May 1986

The research reported here is part of the NBER's research program in Health Economics. Any opinions expressed are those of the authors and not those of the National Bureau of Economic Research. 
Working Paper \#1928

May 1986

\section{An Assessment of the Benefits of Air Pollution Control: The Case of Infant Death}

\section{ABSTRACT}

This paper contains estimates of the impacts of air pollutants on race-specific neonatal mortality rates based on data for heavily populated counties of the U.S. In 1977. Unlike previous research in this area, these estimates are obtained from a well specified behavioral model of the production of health, which is estimated with the appropriate simultaneous equations techniques. The results suggest that sulfur dioxide is the dominant air pollutant in newborn survival outcomes. There is also evidence that an increase in sulfur dioxide raises the neonatal mortality rate by raising the percentage of lowbirth weight births. Based on marginal-willingness-to-pay computations, we estimate that the benefits of a 10 percent reduction in sulfur dioxide levels range between $\$ 54 \mathrm{milli}$ on and $\$ 1.09$ billion in 1977 dollars.

Theodore J. Joyce Department of Economics Iona College New Rochelle, N.Y. 10801 (914) 633-2215
Michael Grossman Department of Economics City University of New York Graduate School

33 West 42nd Street New York, N.Y. 10036 (212) 790-4411
Fred Goldman

Health Services Administration Graduate School of Management and Urban Professions New School for Social Research 66 Fifth Avenue New York, N.Y. 10011 (212) 741-7923 


\section{AN ASSESSMENT OF THE BENEFITS OF AIR POLLUTION CONTROL: THE CASE OF INFANT HEALTH}

Theodore J. Joyce, Michael Grossman, and Fred Goldman*

\section{Introduction}

The controversy surrounding the work of Lave and Seskin (1970, 1973, 1977) on the negative effect of air pollution on aggregate mortality has continued unabated for well over a decade. The debate has sharpened the focus of succeeding research by calling attention to such issues as simultaneity (Gerking and Schulze 1981; Crocker et a1. 1979), confounding (Schwing and MacDonald 1976; Lave and Chappie 1982), functional form (Smith 1976), and the impact of priors on model specification (Atkinson, Crocker, and Murdock 1985). Moreover, efforts to place a monetary value on the benefits of reduced pollution have also evolved. Emphasis on lost productivity (Lave and Seskin 1977) has given way to the theoretically more appealing measure of willingness to pay (Rosen 19.81; Gerking 1983). Crosssectional mortality studies are not a substitute for micro-level data based on individually monitored exposure. Nevertheless, a we11-structured ecological study can provide evidence of potentially causal relationships between pollution and mortality. In addition, aggregate studies remain a practical means of "observing large numbers of people and environments in less than 'rea1 time." (Lave and Chappie 1982, p. 348).

This paper is an attempt to incorporate many of the insights from past studies of pollution and mortality in order to measure the impact of air pollution on race-specific neonatal mortality rates (deaths within the first 27 days of 11 fe per thousand live births) across heavily populated counties 
in the U.S. In 1977. Our study differs from previous research in the pollution area in that it is the first one that simultaneously (1) adopts a behavioral model of the production and demand for health, (2) employs a health indicator (neonatal mortality) that has a well documented relation to a set of medical and nonmedical inputs, ${ }^{1}$ (3) recognizes that the inputs are endogenous variables and therefore uses the proper econometric techniques to obtain the best available estimates from which willingness-to-pay figures can most justifiably be approximated, (4) uses more recent data than Lave and Seskin (1977) and Crocker et al. (1979), and (5) performs an ecological analysis on a larger sample than has previously been attempted. Since the data are more recent they are more relevant to present policy discussions. Moreover, the recent automation of the Environmental Protection Agency's Storage and Retrieval of Aerometric Data (SAROAD) system has improved the accuracy with which data on the pollutants are collected and measured.

The advantages of focusing on neonatal mortality in research on the health effects of air pollution are also worth stressing. The infant mortality rate (deaths of infants within the first 364 days of life per thousand live births) is approximately equal to the mortality rate of 55 to 64 year olds and much higher than age-specific death rates of persons between the ages of 1 and 54. The neonatal mortality rate is twice as large as the postneonatal mortality rate (deaths of infants between the ages of 28 and 364 days per thousand live births). Moreover, accidents, which clearly are not related to pollution, are an important cause of postneonatal deaths. Expectant mothers are unlikely to move during their 
pregnancles. Thus, studies of the relationsh1p between pollution and neonatal mortality are not subject to the criticism that adults who die in one location may have been exposed to pollutants at other locations during their lifetimes.

In spite of the differences between our research and prior work in this area, previous research provides a basis for applylng our framework to study the 1mpacts of a1r pollution on 1nfant health. Lave and Seskin (1973) f1t dose-response functions in which the neonatal mortallty rate (not race-spec1f1c) for 117 Standard Metropol1tan Stat1st1cal Areas (SMSAs) 1n 1960 or 1961 is the dependent varlable. These rates are positively related to total suspended particulate and sulfate concentrations in their ordinary least squares multiple regressions in 1960, and they are posit1vely related to particulate concentrations in 1961. The 1960 sulfate effect and the 1961 particulate effect are statistically significant. Lave and Sesk1n (1977) use the same data set to study the effects of a1r pollution on total infant mortality (deaths of Infants within the f1rst 364 days If IIfe), race-adjusted 1nfant mortality, and race-specific Infant mortal1ty. In general, the particulate regression coefficient is positive and statistically significant, while the sulfate coefficient is positive and 1nsignificant. Futhermore, in a smaller sample of SMSAs, in which add1tional pollutants were also examined, sulfur dloxide evidences a statistcally significant association with infant mortality. Crocker et al. (1979), In a sample of $60 \mathrm{U.S}$. c1t1es in 1970, report a positive and sign1flcant effect of sulfur dioxide concentrations in the a1r on deaths from early Infant diseases (not race-spec1f1c), most of which occur w1th1n the 
first 27 days of $11 \mathrm{fe}$. The particulate coefficient in their regression is positive and not significant, and the nitrogen dioxide coefficient is negat1ve and not significant. Mendelsohn and orcutt (1978) find that nitrates and particulates have a statistically significant effect on white male Infant mortality rates but no effect on female rates across 404 county groups in 1970. These results are not consistent with their primary finding that sulfates are positively related to mortality among adults and that the effect increases with age.

\section{Analyt1cal Framework}

Following Grossman and Jacobow1tz (1981), Rosenzwe1g and Schultz (1981, 1982, 1983a, 1983b), Corman and Grossman (1985), Corman, Joyce, and Grossman (1985), and Joyce (1985), we assume that the parents' ut1lity function depends on their own consumption, the number of births, and the survival probability of each of their offspring (assumed to be the same for each infant in a given famlly). Both the number of births and the survival probability are endogenous variables. In particular, the survival probability production function depends upon such endogenous inputs as the quantity and quality of medical care, maternal cigarette smoking, the use of abortion services, and the use of family planning services. ${ }^{2}$ In addition, the production function is affected by the reproductive efficiency of the mother, including the unobserved blologically endowed probability that her Infant will survive the f1rst month of life, and other aspects of her eff1clency in household production. Finally, the production function depends on the quality of the environment as reflected by the levels of various pollutants. ${ }^{3}$ 
Maximization of the parents' utility function subject to production and resource constraints generates a demand function for survival in which the survival probabllity or 1 ts complement, the neonatal mortality rate, is related to input prices (whose direct and indirect cost components are negatively related to input avallability), efficlency, Income, environmental quality, and tastes. The interaction between the survival demand and production function determines demand functions for medical care and other endogenous inputs. These demand functions depend on the same set of variables as the demand function for survival. Environmental quality is a relevant argument in the input demand functions because high levels of pollution may, for example, Induce Individuals to obtain larger quantities of preventive or curative medical care or to smoke less.

The preceding Ideas are formalized in a structural equations model that incorporates the relationship between neonatal mortality and 1 ts two most proximate determinants - low birth welght and prematurity. In particular, there is an overwhelming amount of evidence that low birth weight (less than or equal to 2,500 grams or 5.5 pounds) is the most important endogenous risk factor in neonatal survival outcomes (for example, harris 1982; Lewit 1983; Institute of Medicine 1985). There also is a considerable amount of evidence that prematurity, reflected by gestational ages of 36 weeks or less, is the most important and most proximate endogenous risk factor in birth welght outcomes (for example, Taffel 1980; Rosenzweig and Schultz 1981, 1982, 1983b; Harr1s 1982; Lew1t 1983). The system of equations is designed to obtain estimates of the direct and indirect (through low birth welght) effects of five basic health inputs and air 
pollution on neonatal mortality. These inputs are prenatal medical care, perinatal and neonatal care, the use of abortion services, the use of contraceptive services, and maternal cigarette smoking. The equations in the model have meaningful interpretations both at the family level and at the county level. The latter is the unit to which the empirical analysis in this paper pertains.

The basic model consists of the following nine equations:

$$
\begin{aligned}
1-\pi & =f_{1}(n, m, a, c, q, b, e) \\
b & =f_{2}(m, a, c, q, s, g, e) \\
g & =f_{3}(m, a, c, q, r, e) \\
r & =f_{4}(a, c, x, e) \\
n & =f_{5}(p, y, q, x, e) \\
m & =f_{6}(p, y, q, x, e) \\
a & =f_{7}(p, y, q, x, e) \\
c & =f_{8}(p, y, q, x, e) \\
s & =f_{9}(p, y, q, x, e) .
\end{aligned}
$$

Equations (1), (2), (3), and (4) are production functions, while equations (5)-(9) are input demand functions. In equation (1) the probability that an infant dies within the first month of life or the neonatal mortality rate at the county level ( $1-\pi$, where $\pi$ is the survival probability) is shown as a vector of perinatal and neonatal care inputs ( $n$ ), a vector of prenatal medical inputs (m), the use of abortion services (a), the use of contraceptive services (c), environmental quality ( $q$, which rises as the level of alr pollution falls), the probability that the infant is born Iight (b), and the infant's biological endowment (e). ${ }^{4}$ In equation (2) the 
probability of a light (2,500 grams or less) birth or the fraction of light births in a county is a function of the variables in equation (1) except neonatal care and also depends on maternal cigarette smoking (s) and the probability that the birth is premature ( $g$, which represents the probability that gestational age is less than 37 weeks). In equation (3) the probability of a premature birth or the county-level fraction of such births is related to the variables in equation (2) except cigaret te smoking and also an endogenous risk factor in prematurity such as mother's age at birth $(r) .5$ In equation (4) the endogenous risk factor is expressed as a function of its determinants, including an observed exogenous risk variable ( $x$, a measure of which is specified in Section III). In equations (5)-(9) the inputs depend on a vector of price and availability measures ( $p$ ), socioeconomic characteristics that reflect command over resources and tastes $(y)$, the exogenous risk measure, environmental quality, and the biological endowment. Each of the nine equations contains an unspecified disturbance term $\left(u_{i}, i=1, \ldots, 9\right)$ that is uncorrelated with $u_{j}(j \neq i)$. In addition each $u_{1}$ is uncorrelated with the set of right-hand side variables in the equation that contains it.

The four production functions are structural equations because they show relationships among endogenous variables. Substitution of the input demand functions and equations (3) and (4) into (I) and (2) yields demand functions for survival and birth weight:

$$
\begin{aligned}
1-\pi & =f_{10}(p, y, q, x, e) \\
b & =f_{11}(p, y, q, x, e) .
\end{aligned}
$$

These are reduced form equations because only exogenous variables appear on 
their right-hand sides. Together with the input demand functions, they constitute the reduced form of the model.

Given our interest in obtaining marginal-willingness-to-pay measures (see below), we focus on the estimation of the structural neonatal mortality rate production function (1) and the quasi-structural mortality production function obtained by substituting equations (2), (3), ankd (4) into equation (1):

$$
1-\pi=f_{12}(n, m, a, c, q, s, x, e) .
$$

This procedure enables us to calculate the direct and indirect (through low birth weight) effects of the basic health inputs and environmental quality on neonatal mortality.

If the infant's biological endowment (e) were an observed variable, unbiased estimates of the production function could be obtained by ordinary least squares. Since this is not the case, the endowment must be treated as one component of the disturbance term in each equation. Hence, our model generates a recursive system of equations whose disturbance terms may be correlated. In particular, although the researcher has no information about the endowment, the mother and her physician have at least some information about 1t. This information is likely to lead mothers with poor endowed birth outcomes and their physicians to try to offset these unfavorable prospects by choosing a different $\mathrm{mlx}$ of inputs than other mothers (Rosenzweig and Schultz 1981, 1982, 1983a, 1983b; Harris 1982).

To be specific, mothers with poor endowments have incentives to seek prenatal care earlier in their pregnancies than other women, and their physiclans are likely to obtain larger amounts of neonatal care for them. In 
addition, such women are more likely to smoke less, to abort thetr pregnancies, or to use contraceptive services. Under these circumstances, ordinary least squares estimates of the parameters of the production function are blased and Inconsistent because the Inputs are correlated with the disturbance term, which reflects in part the endowment. In particular, the effects of the inputs on favorable infant health outcomes are understated. 6

To ctrcumvent the above problem, production functions are obtained by two-stage least squares. In the first stage of this procedure, the Input demand functions and the reduced form birth welght equation are fitted with explanatory vartables that are uncorrelated with the endowment by assumpt1on. In the second stage the predicted values of the inputs and low birth welght rather than the actual values are used as regressors.

It should be noted that the blases that arise when equation (12) is estimated by ordinary least squares are Iikely to be more severe than the biases that arise when equation (1) is estimated in a simflar manner. This is because equation (1) Includes birth weight, which may be a very useful proxy for the infant's endowed probabllity of survival. Put differently, It is posstble that the endowment has no effect or a smaller effect on neonatal mortality with low birth weight held constant. We explore this proposition in emplrical tests discussed in Sections III and IV.

Certain restrictions must be imposed to insure that each equation in the system satisfles rank and order conditions for identification. The most Important restrictions are: (1) neonatal care has no tmpact on low birth weight; (2) clgarette smoking affects neonatal mortality only through Its effect on low birth welght; (3) prematurity affects mortality only 
through low birth weight; and (4) cigarette smoking has no effect on prematurity. With regard to the first restriction, decisions to use neonatal care services are made after birth, and low birth weight causes more use of these services. $^{7}$ For the other assumptions, there is considerable supporting evidence. ${ }^{8}$

To allocate scarce resources among competing goals, policy makers require information about the dollar values of the potential health benefits associated with improvements in environmental quality (reductions in pollution). The benefits of a small (incremental) reduction in pollution is given by marginal willingness to pay, defined as the amount of income that mist be taken from an individual to leave him as well off as previously (to hold his level of utility constant) when the level of pollution declines. Marginal willingness to pay can be obtained directly from the health production function and is independent of the demand function (Freeman 1979; Rosen 1981; Gerking 1983; Harrington and Portney 1983). It is given by the marginal product of environmental quality in the production function multiplied by the ratio of the price of an endogenous health input such as prenatal medical care utilization to the marginal product of that input. The ratio just mentioned coincides with the marginal cost of producing health.

In the context of our model, the marginal willingness to pay (dy, defined to be positive) for an increase in environmental quality of $\mathrm{dq}$ is

$$
\mathrm{dy}=\pi_{\mathrm{q}}\left(\mathrm{p} / \pi_{\mathrm{m}}\right) \mathrm{dq} \text {. }
$$

Here a subscript denotes a partial derivative, $\pi_{q}$ is the marginal product of environmental quality (the increase in the survival probability caused 
by a sma11 increase in environmental quality), and $\pi_{m}$ is the marginal product of prenatal care. In equilibrium the ratio of the price of an input used solely to produce infant health to its marginal product is the same for all inputs. Therefore, if $p^{\prime}$ is the price of neonatal care and $\pi_{n}$ is 1ts marginal product, an alternative estimate of marginal willingness to pay 18 given by

$$
d y=\pi_{q}\left(p^{\prime} / \pi_{n}\right) d q \text {. }
$$

Margina1-w111ingness-to-pay measures based on equations (13) and (14) are presented in Section IV. ${ }^{9}$ Particularly in the case of prenatal care, the quasi-structural production function is the most relevant one to use in the computations. This is because prenatal care has its main effect on neonatal mortality via low birth weight (for example, Corman, Joyce, and Grossman 1985). 10

Note that in a somewhat more general model where other aspects of health in addition to the survival of neonates enters the utility function, the formula for marginal willingness to pay given by equation (13) or (14) would be the correct theoretical construct if and only if environmental quality, prenatal care, and neonatal care affected neonatal mortality outcomes alone. However, if environmental quality affects the health of children, adolescents, and adults and other aspects of their well being such as cognitive development, then we understate willingness to pay. Finally, if medical care also affects those outcomes, which is plausible since they are known to depend on birth weight and health in the first year of life (for example, Edwards and Grossman 1979; Shakotko, Edwards, and Grossman 1981), the direction of the bias is indeterminant. These caveats should be kept in mind when the estimates are presented. 
III. Empirical Implementation

A. Measurement of Variables

The neonatal mortality rate production functions are estimated with a data set that pertains to the 677 most populated counties of the United States. These are counties with a population of at least 50,000 persons in 1970.11 We have constructed this data base from a variety of sources and have described it in detafl in Corman and Grossman (1985), Corman, Joyce, and Grossman (1985), and Joyce, Grossman, and Goldman (1986). Table 1 contains definitions, means, and standard deviations of the variables used in this study.

The mortality production functions focus on the neonatal mortality rate as opposed to the postneonatal mortality rate or the total infant death rate. This strategy is adopted because most neonatal deaths are caused by congenital anomalities, prematurity, and complications of delivery. These conditions are more sensitive to improved prenatal, perinatal, and neonatal care than are the infectious diseases and accidents that contribute to postneonatal mortality. Moreover, accidents clearly are not related to pollution, and expectant mothers are unlikely to move during their pregnancies.

Separate regressions are fitted for white and black outcomes. Black infant health levels are much lower than white levels. For example, in 1977 the black neonatal mortality rate was roughly twice as large as the white rate. In a non-race-specific regression, one would enter the percentage of black births to control for race differences. But this variable would be highly correlated with the use of prenatal care and other inputs. 
Table 1

Definition, Means, and Standard Deviation of Variables ${ }^{a}$

Neonatal mortality rate*

Teenage family planning users* ${ }^{b}$

\section{Abortion rate}

Prenatal care*

Neonatal intensive care*

\section{Cigarettes}

Low birth weight*

High risk women $*^{\mathrm{b}}$

Carbon monoxide

Lead
Three-year average neonatal mortality rate centered on 1977; deaths of Infants less than 28 days old per 1,000 live births.

$\left(\mu_{w}=8.837, \sigma_{w}=1.595, \mu_{b}=16.387 ; \sigma_{b}=3.299\right)$

Percentage of women aged 15-19 who used organized family planning clinics in 1975

$\left(\mu_{w}=9.067, \sigma_{w}=6.290, \mu_{b}=24.176, \sigma_{b}=9.656\right)$

Three-year average state-specific resident abortion rate centered on 1976; abortions performed on state residents per 1,000 women aged $15-44$

$\left(\mu_{w}=24.969, \sigma_{w}=8.716, \mu_{b}=24.754, \sigma_{b}=8.602\right)$

Three-year average fraction of live births for which prenatal care began in the first trimester (first three months) of pregnancy centered on 1977

$\left(\mu_{w}=.781, \sigma_{w}=.083, \mu_{b}=.594, \sigma_{b}=.102\right)$

Sum of state-specific hospital inpatient days in Level II, or Level III, or Levels II and III neonatal intensive care units in 1979 per statespecific three-year average number of births centered on 1977

$\left(\mu_{w}=.641, \sigma_{w}=.385, \mu_{b}=1.501, \sigma_{b}=1.011\right)$

State-specific daily number of cigarettes smoked per adult 18 years and older in 1976

$\left(\mu_{w}=7.416, \sigma_{w}=.511, \mu_{b}=7.486, \sigma_{b}=.350\right)$

Three-year average percentage of low-birth weight (2,500 grams or less) live births centered on 1977 $\left(\mu_{w}=5.992, \sigma_{w}=.741, \mu_{b}=13.016, \sigma_{b}=1.228\right)$

Number of women $15-19$ and $40-44$ as a fraction of women $15-44$ in 1975.

$\left(\mu_{w}=.335, \sigma_{w}=.022, \mu_{b}=.350, \sigma_{b}=.026\right)$

Four-year average carbon monoxide level for the period 1975-1978; milligrams per cubic meter $\left(\mu_{w}=2.320, \sigma_{w}=1.147, \mu_{b}=2.325, \sigma_{b}=1.063\right)$

Four-year average lead level for the period 19751978; micrograms per cubic meter

$$
\left(\mu_{w}=.843, \sigma_{w}=.724, \mu_{b}=.794, \sigma_{b}=.617\right)
$$


Table 1 (continued)

Sulfur dioxide

Particulates

Nitrogen dioxide
Four-year average sulfur dioxide level for the period 1975-1978; micrograms per cubic meter $\left(\mu_{w_{326}}=30.826, \sigma_{w}=18.810, \mu_{b}=34.858, \sigma_{b}=\right.$
20.326

Four-year average total suspended particulates level for the period 1975-1978; micrograms per cublc meter

$\left(\mu_{w}=71.053, \sigma_{w}=22.905, \mu_{b}=70.366, \sigma_{b}=\right.$ $17.755)$

Four-year average nitrogen dioxide level for the period 1975-1978; micrograms per cubic meter $\left(\mu_{w_{1}}=54.094, \sigma_{w}=30.908, \mu_{b}=53.192, \sigma_{b}=\right.$
$30.878)$

$a_{A n}$ asterisk (*) next to a variable means that it is race-specific. All variables are county-specific unless otherwise indicated. The symbols $\mu_{w}, \sigma_{w}, \mu_{b}$, and $\sigma_{b}$ denote the white mean, the white standard deviation, the black mean, and the black standard deviation, respectively. Means and standard deviations are weighted by the race-specific total number of births in the period 1976-1978. With the exception of the pollutants, the white data pertain to 677 counties, and the black data pertain to 357 counties. The pollution measures pertain to the first five subsamples for each race defined in the text. The number of counties in each subsample is Indicated in Tables 2, 3, and 4 .

bVariable is ava1lable for whites and nonwhites as opposed to whites and blacks. 
By fitting race-specific regresstons, multicollinearity is reduced, and the coefficlents of the inputs and the pollutants are allowed to vary between races. Moreover, In preliminary regressions we tested and rejected the hypothesis that slope coefficlents but not intercepts are the same for whites and blacks.

Counties are our units of observation rather than Standard Metropolitan Statisitical Areas (SMSAs) or states because counties tend to be more homogeneous with respect to key variables such as income, schooling, medical resources, and pollution. Some counties are so sparsely populated, however, that people may receive medical care outside the county. Also, small countles, whth few births, experfence large fluctuations in birth rates simply due to random movements. The problems with county data are reduced by Including only countles with a population of at least 50,000 persons in 1970. A county must also have at least 5,000 blacks for incluston In the black data base. There are 677 counties in the white sample and 357 counties in the black sample. The counties in the white data set accounted for approximately 80 percent of the white population of the U.S. In 1970, and the counties in the black data set accounted for a simflar percentage of the black population of the U.S. In that year. In addition to selecting large counties, we attenuate random elements by employlng a three-year average of the race-specific neonatal mortality rate for the pertod 1976-1978 as the dependent variable.

The air pollution variables were taken from the Environmental Protection Agency's Storage and Retrieval of Aerometric Data (SAROAD). This is an automated data processing system used by EPA for the storage of 
data concerning concentrations of the six criteria alr pollutants in the atmosphere: carbon monoxide, lead, sulfur dioxide, total suspended particulates, nitrogen dioxide, and ozone. These are pollutants for which National Ambient Air Quality Standards (NAAQS) have been established as part of the Clean Air Act. All major clties and one-third of all counties have at least one monitoring station, although a number of stations are not operative, and many others do not monitor all the pollutants. In preliminary regressions (not shown in Section IV), ozone never had a positive and statistically significant coefficient. Therefore, 1t was discarded from the set of pollutants.

The raw data in SAROAD take the form of hourly concentrations of carbon monoxide, sulfur dioxide, nitrogen dioxide and weekly concentrations of lead and total suspended particulates. ${ }^{12}$ To obtain county-specific estimates of pollution the following algorithm was used. Counties in the data base were divided into census tracts or minor civil divisions in counties with no census tracts. Exposure measures for these smaller units by pollutant and year were computed as weighted (by the number of readings) averages of the monttor averages. Then county averages were obtalned as weighted averages of the tract or the division averages, where the weight was the population density (population per square mile in 1980) of each tract or division in a given county. Finally, the pollutant-specific fouryear average for the county was calculated as a simple average of the four annual averages. 13 If data were missing for one or two years, a three- or two-year average was computed. If an annual average was avallable for a single year alone, that figure was used. 14 
Complete data on the five pollutants are avallable for 102 of the 677 counties in the white sample and for 86 of the 357 counties in the black sample. Instead of limiting our production functions to these two subsamples, we define six subsamples for each race. The first five include counties in which a given pollutant measure is avallable, regardless of whether data on the other four pollutants are present. Each of the five subsamples is used to estimate a production function in which the pollutant at issue alone and the health inputs are included as regressors. The sixth subsample includes counties with data on all pollutants and is used to fit a production function in which the five pollutants are entered as explanatory variables. It is worth noting that the means and standard deviations of the neonatal mortality rate and the health inputs are very similar in the seven samples for each race (the total sample and the six subsamples). The five basic inputs used in the production of infant health are neonatal intensive use, prenatal care use, the abortion rate, the use of family planning clinics by teenagers, and adult per captta smoking. Except for smoking, all the inputs should be negatively related to the measures of infant health described above. ${ }^{15}$ Low birth welght, the endogenous risk factor in the structural neonatal mortality rate production function [equation (1)] Is given by a three-year average of the percentage of births of 2,500 grams or less centered on 1977. The final explanatory varlable represents the exogenous risk factor $(x)$ in the quasi-structural production function [equation (12)]. For this variable, we use the number of women who are efther teens or in their forties as a fraction of all women of childbearing age In 1975. These are the age groups considered most at risk for negative birth outcomes. 


\section{B. Estimation and Functional Form}

The neonatal mortality equations (1) and (12) are fitted using a twostage least squares procedure for the reasons discussed in Section II. Specifically, the unobserved health endowment, which is captured in the error term of the production function, is belleved to be correlated with the use of the health inputs. Rosenzwelg and Schultz (1982) refer to this problem as population "heterogeneity." Such "heterogeneity" causes ordinary least squares (OLS) estimates to be biased and inconsistent. If Income and input avallability measures are uncorrelated with the health endowment, however, these variables can serve as instruments in a two-stage least squares (TSLS) estimation procedure.

We test for the significance of the correlation between the production function residuals and the health 1nputs, using Wu's $\mathrm{T}_{2}$ statist1c (Wu 1973) as described by Nakamura and Nakamura (1981). If the null hypothesis of zero correlation between the error term and the regressors is not rejected, then OLS is an appropriate technique. For this reason, we perform oLS as well as the two-stage least squares technique on equations (1) and (12). A comparison of Wu statistics for equations (1) and (12) allows us to examine whether birth weight is a reasonable proxy for the health endowment.

In the first stage of our two-stage estimation procedure, birth weight, prenatal care, neonatal intensive care, abortion, and organized family planning use are predicted on the basis of the pollutants, female schooling, female poverty levels, the fraction of high-risk women, neonatal Intensive care avallability, abortion avaflability, organized family planning avallability, maternal and infant care project avallability, com- 
munity health center avallability, and the Medicaid program. With the exception of the pollutants, these right-hand side variables are similar to those used In Corman and Grossman's (1985) reduced form estimates. Predicted values of the five endogenous variables are then entered into the neonatal mortality equations. We do not estimate values for the smoking variable in a first stage because the smoking variable was already estimated on the basis of income, price, education, age, sex and race, as described in Joyce, Grossman, and Goldman (1986). Our procedure is based on the reasonable assumption that prenatal and neonatal input availability measures have zero coefficients in the cigarette demand function. 16 Since the neonatal survival probability $(\pi)$ ranges between zero and one, we specify the production function as a logistic equation:

$$
\pi=\left[1+\exp \left(-\alpha-\beta_{1} \ln q-\beta_{2} \ln m-\beta_{3} \ln n-\beta_{4} \ln w\right)\right]^{-1} .
$$

Here $q$ is environmental quality, $m$ is prenatal medical care, $n$ is neonatal Intensive care, $w$ is a vector of additional explanatory variables, in stands for natural logarithm, and the disturbance term is suppressed. By solving for the logarithm of the odds of survival relative to death $[\pi /(1-\pi)]$, one transforms the logistic function into a linear equation:

$$
\ln [\pi /(1-\pi)]=a+\beta_{1} \ln q+\beta_{2} \ln m+\beta_{3} \ln n+\beta_{4} \ln w,
$$

which is called the logit function. The logit coefficient $\beta_{1}$, for example, shows the percentage change in the odds of survival for a one percent change in the quality of the environment. Given that the production function is logistic, the marginal-willingness-to-pay measure [see equations (13) and (14)] becomes 17

$$
\mathrm{dy}=\mathrm{p}\left(\beta_{1} / \beta_{2}\right)(\mathrm{w} / \mathrm{q}) \mathrm{dq}=\mathrm{p}^{\prime}\left(\beta_{1} / \beta_{3}\right)(\mathrm{n} / \mathrm{q}) \mathrm{dq},
$$


where $p$ is the price of prenatal care and $p^{\prime}$ is the price of neonatal intensive care. According to equation (17), marginal willingness to pay falls as the quality of the environment rises or as the level of pollution falls. Moreover, willingness to pay rises as prenatal care or neonatal intensive care rises. These extremely appealing theoretical properties are the result of the assumption that the logit function is linear in the logarithms of $\mathrm{m}, \mathrm{q}$, and $\mathrm{n}$, and justify this assumption. ${ }^{18}$ In addition, if interactions among pollutants are ignored, it is logical to define the level of pollution (z) as

$$
z=q^{-1} \text {. }
$$

Since we take $\ln [(1-\pi) / \pi]$ as the dependent variable, the final form of the equation to be fitted is:

$$
\ln [(1-\pi) / \pi]=-\alpha+\beta_{1} \ln z-\beta_{2} \ln m-\beta_{3} \ln \mathrm{n}-\mathrm{B}_{4} \ln \mathrm{w} .
$$

Note that the marginal willingness to pay for a percentage increase in environmental quality ( $\ln$ q) is exactly the same as the marginal willingness to pay for a percentage reduction in pollution ( $d \ln z)$ : $\mathrm{dy}=\mathrm{p}\left(\beta_{1} / \beta_{2}\right) \mathrm{m} \mathrm{d} \ln q=-p\left(\beta_{1} / \beta_{2}\right) \mathrm{m} d \ln z=-\mathrm{p}^{\prime}\left(\beta_{1} / \beta_{3}\right) \mathrm{n} \mathrm{d} \ln z \cdot$ (20) Equation (19) is estimated with all explanatory variables except the percentage of teenagers who use organized family planning services and the fraction of high-risk women in natural logarithms. The former variable is entered in arithmetic form because it equals zero in certain counties, while the latter is entered in arithmetic form because it is not an endogenous health input. The logit coefficients of prenatal care, abortion, family planning, and neonatal intensive care are expected to be negative, and the coefficients of the pollutants, cigarette smoking, low birth 
weight, and high-risk women are expected to be positive. Maddala (1983) shows that a weighted least squares procedure should be employed to fit a logit model to grouped data. The weights are given by $\left[B_{j} \pi_{j}\left(1-\pi_{j}\right)\right]^{1 / 2}$, where $B_{j}$ is the number of race-specific births in the $j^{\text {th }}$ county. Results obtained with such alternative function forms as the linear and log-linear models do not differ in a qualitative sense from those presented in Section IV. 19

\section{Results}

Ordinary least squares (OLS) and two-stage least squares (TSLS) estimates of the white and black logit neonatal mortality rate production functions are contained in Tables 2 and 3 . Panel $A$ in each table pertains to the full white and black samples. No pollution measures are included in the four regressions in panel $A$. The first two regressions $(2-1,2-2,3-1$, and 3-2) exclude the endogenous risk factor of low birth weight while the ensuing two (2-3,2-4, 3-3 and 3-4) include the percentage of low-birth weight births as an explanatory varlable. Panel B of Tables 2 and 3 pertains to the white and black sulfur dioxide samples. We present detailed results for the sulfur dioxide sample because, unlike the other four pollutants, sulfur dioxide has a consistently negative and statistically significant impact on newborn survival. As shown below, this is true regardless of whether sulfur dioxide is the sole pollutant or one of five in the production function. As with Panel A, Panel B contains OLS and TSLS estimates of the production functions with and without the endogenous risk factor. Finally, Panel $C$ of Tables 2 and 3 presents the production function estimates with all five pollutants. Panel $C$ follows the same format as 


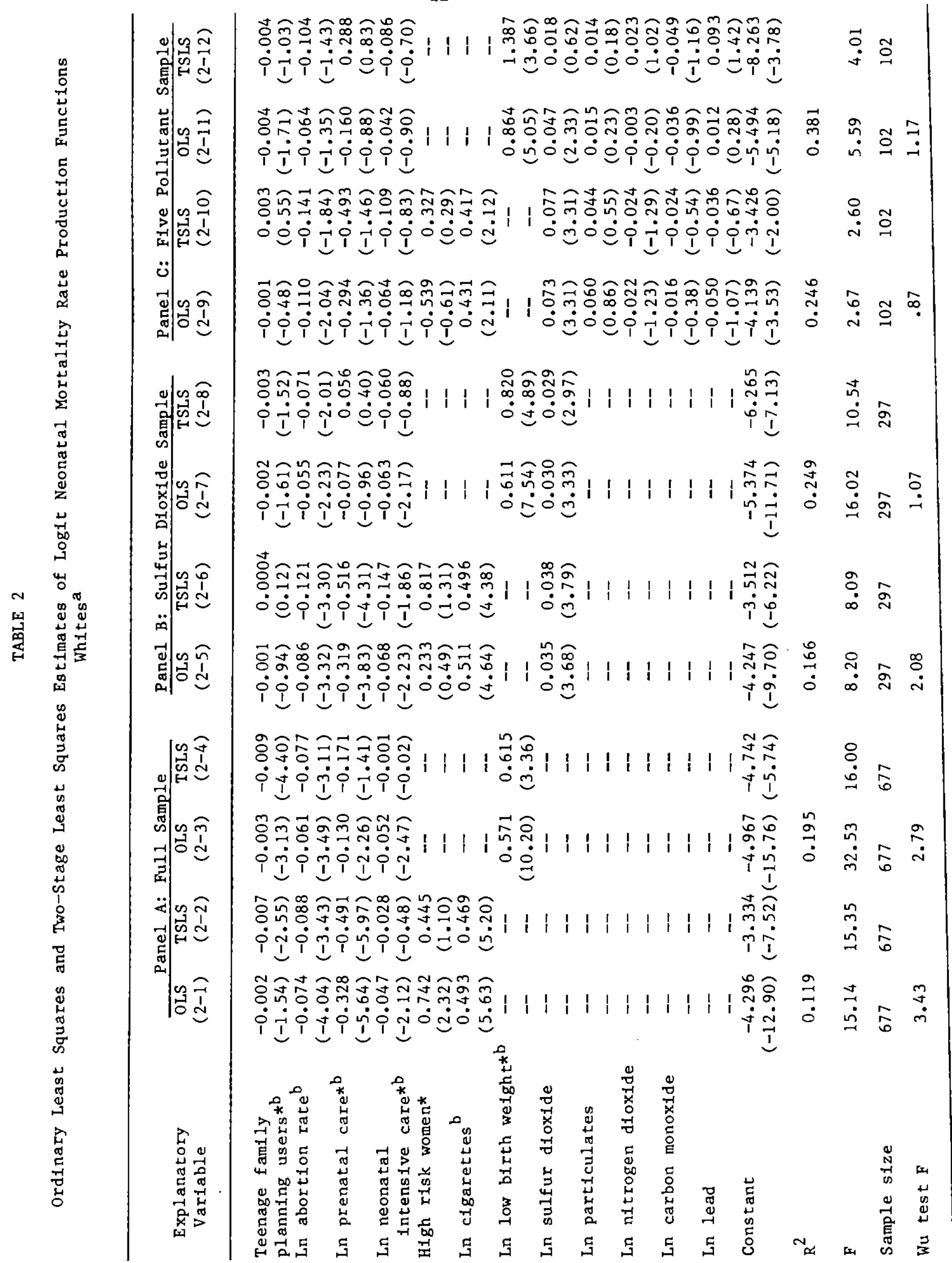


Notes to Table 2

${ }^{a}$ Ln stands for natural logarithm. Asymptotic t-ratios in parentheses. The critical asymptotic t-ratios at the 5 percent level are 1.64 for a onetailed test and 1.96 for a two-tailed test. In this table and the others that contain regression results, the $F$-ratio associated with each regression is significant at the 1 percent level unless otherwise indicated. An asterisk (*) next to a variable means it is race specific. Each pollution measure is the natural logarithm of the county-specific geometric mean.

bEndogenous in TSLS equations. 


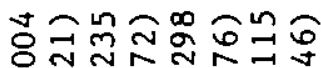

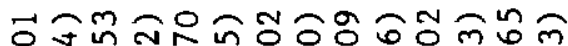

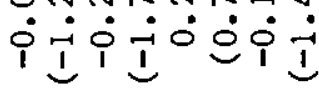

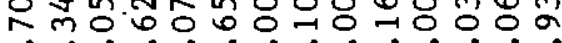

$\dot{0} \dot{0} \dot{0} \dot{0} \dot{0} \dot{0} \dot{0} \dot{0} \dot{0} \dot{0} \dot{0} \dot{i}$

in

$\therefore \quad \infty$

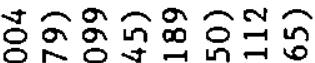

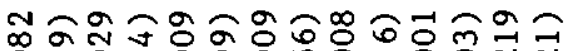

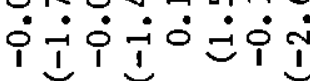

-10
0

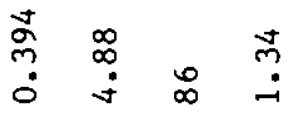

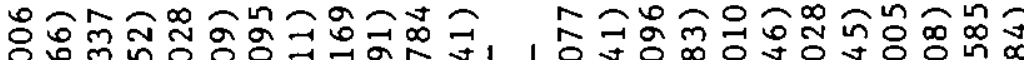

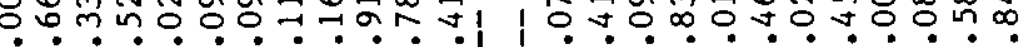

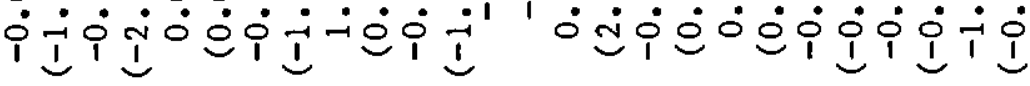

in

$\stackrel{\infty}{-} \infty$

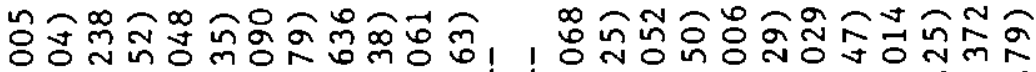

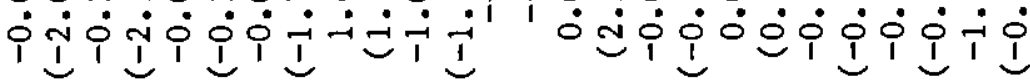

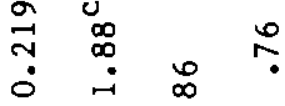

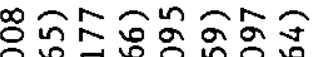

点 0

îj

$\stackrel{\substack{0 \\ \infty}}{0} 0$

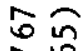

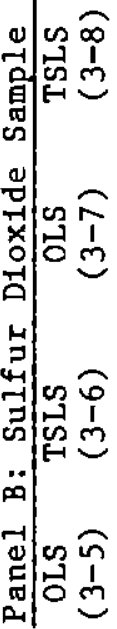

$\dot{0} \dot{0} \dot{0}$

$\dot{\sim} \dot{\sim}$

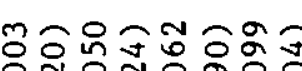

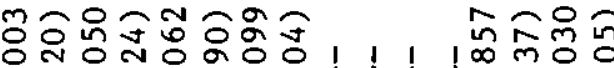

$\dot{1} \dot{1} \dot{1} \underset{1}{0} \dot{0} \dot{0}$

๓

ํำ

$\dot{0} \dot{0} \dot{0}$

mั

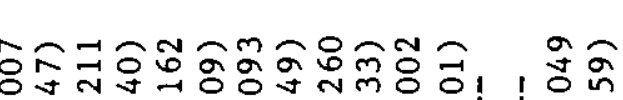

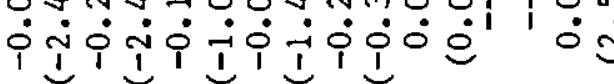

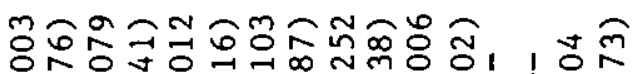

i

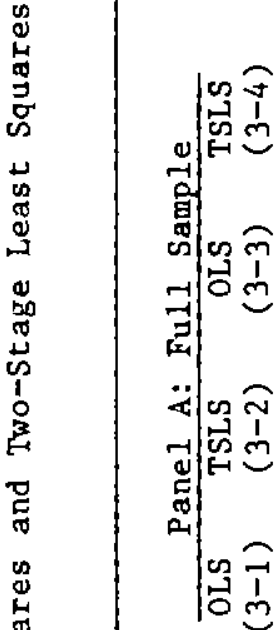

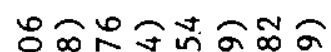

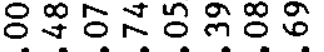

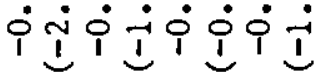

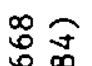

$\stackrel{0}{0}$

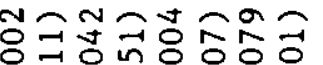

$\dot{i} \dot{i} \dot{i} \dot{i} \dot{0} \dot{i}$

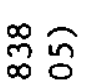

$\stackrel{\infty}{\infty}:$

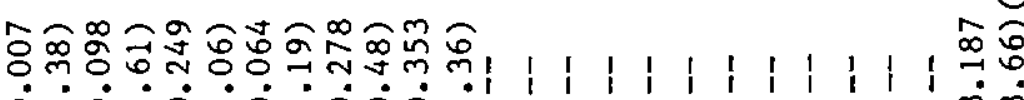

$\dot{i} \dot{i} \dot{i} \dot{i} \dot{i} \dot{i} \dot{i}=\dot{0} \dot{0} \dot{0}=$

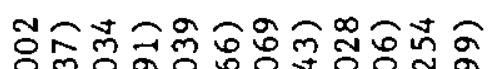

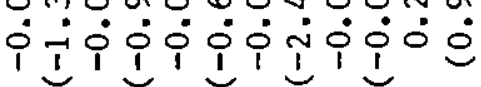

究。

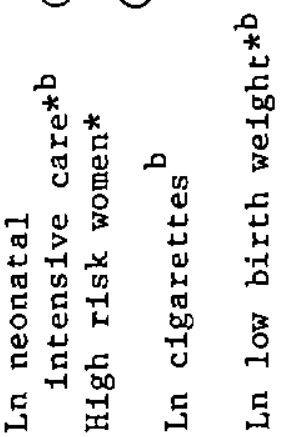

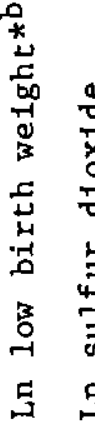

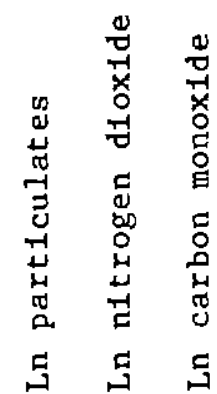

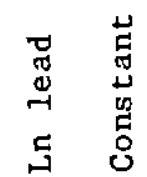

守

in

$\vec{I}$

$\begin{array}{llll}\stackrel{N}{N} & \infty & 0 & \infty \\ 0 & 0 & \ddots & \sim\end{array}$

总

ڤ̊요

نั

* م

$\rightarrow$ t

当

$4=$

(1)

元

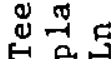

5 
Panels $A$ and $B$.

An overview of the results in Pane1 A of Tables 2 and 3 indicates that all the health inputs have the anticipated signs. In particular, in the specifications that orit the percentage of low-birth weight births, the logit coefficients of teenage family planning use, abortion, prenatal care, and neonatal intensive care are negative, while the logit coefficient of cigarette smoking is positive. In the case of whites, 14 out of the 18 coefficients are significant at the 5 percent level. With respect to the blacks, 13 of 18 coefficients have t-ratios greater than one. In most cases the magnitudes and significance levels of the input coefficients do not vary dramatically among the three samples (Panels $\mathrm{A}, \mathrm{B}$, and $\mathrm{C}$ ). A Chow test was used to determine whether the neonatal mortality regressions in the samples that contain pollutants differed from the regressions in the non-pollution samples. The null hypothesis of no difference was never rejected when comparing the four sulfur dioxide regressions with the regressions from counties that have no sulfur dioxide monitors. When the same test was performed with the five pollutant sample, the null hypothesis of no difference was rejected in two out of the four cases at the 5 percent leve1. 20

A comparison of the TSLS and OLS estimates reveals that the TSLS coefficients of prenatal care, abortion, and family planning are substantially larger than the corresponding OLS coefficients. These findings reflect decisions by women with unobserved poor endowed birth outcomes to initiate care earlier in their pregnancies than other women. In addition, such women are more likely to abort their pregnancies and use organized family 
planning services. The existence of these relationships biases oLs estimates of the production function parameters of prenatal care, abortion, and family planning toward zero. Furthermore, the result that this difference is greater for blacks underscores the argument by Rosenzweig and Schultz (1983a) that OLS and other direct correlational estimates of prenatal care's effect on early infant deaths may be serfously underestimating 1ts true 1mpact on 1nfant health.

Based on the Wu test, the null hypothes 1s of zero correlation between the health 1nputs and the disturbance term is rejected at the 5 percent level in the full-sample, white regressions $(2-1,2-3)$. In the case of blacks, the null hypothes 1s is rejected at the 10 percent level in regression (3-1). In the smaller samples which contain data on pollutants, the nuli hypothesis can only be rejected once (regression 3-7). It is noteworthy that in the full sample the Wu statistic falls when birth welght 1s held constant. Similar results were obtalned by Rosenzweig and Schultz (1982, 1983b), Corman, Joyce, and Grossman (1985) and Joyce (1985). Th1s suggests that in the estimation of infant health production functions the relevant intermediate birth outcome may be an effective proxy for endowed health. Based on this result and the previous work fust cited, we emphasize the TSLS estimates in specifications that exclude the percentage of low-birth weight births and the oLS estimates in the equations that include this risk factor.

The results from including sulfur dloxide as an exogenous determinant of neonatal mortality are presented in Panel $B$ of Tables 2 and 3 . In all elght specifications the coefficient of sulfur dioxide is significant at 
the 5 percent level or better. Each of the other four pollutants was also treated as an exogenous determinant of neonatal mortality. Table 4 presents the coefficients and t-ratios of each pollutant estimated by OLS as well as TSLS for both the white and black samples. These results reveal that carbon monoxide and total suspended particulates have the most consistently negative impact on early infant survival. However, when all five pollutants are employed as regressors, sulfur dioxide is the only significant predictor of neonatal mortality (Panel C, Tables 2 and 3 ).

The environmental quality effects in Panel $C$ of Tables 2 and 3 are our most refined estimates because they include the full set of pollutants. The conclusion that sulfur dioxide is the dominant pollutant should be interpreted with some caution due to the intercorrelation among the five measures. Nevertheless, this result is consistent with the regressions that consider each pollutant one at a time, for the logit coefficients of sulfur dioxide are the only ones that are always significant at conventional levels. Note that the positive and significant sulfur dioxide coefficients in regressions $(2-10),(2-11)$, and (3-10) are not artifacts of the negative coefficients of some of the other pollutants. In specifications not shown, we deleted the pollutants with negative coefficients in Panel $c$. The magnitude and significance of sulfur dioxide was unaltered. There is also evidence that sulfur dioxide impacts on early infant deaths by raising the percentage of low-birth weight births. Comparing regressions 2-6 with 2-7 and 3-6 with 3-7, one sees that the inclusion of low birth weight lowers the white sulfur dioxide coefficient by 21 percent and lowers the black sulfur dioxide coefficient by 39 percent. The same 


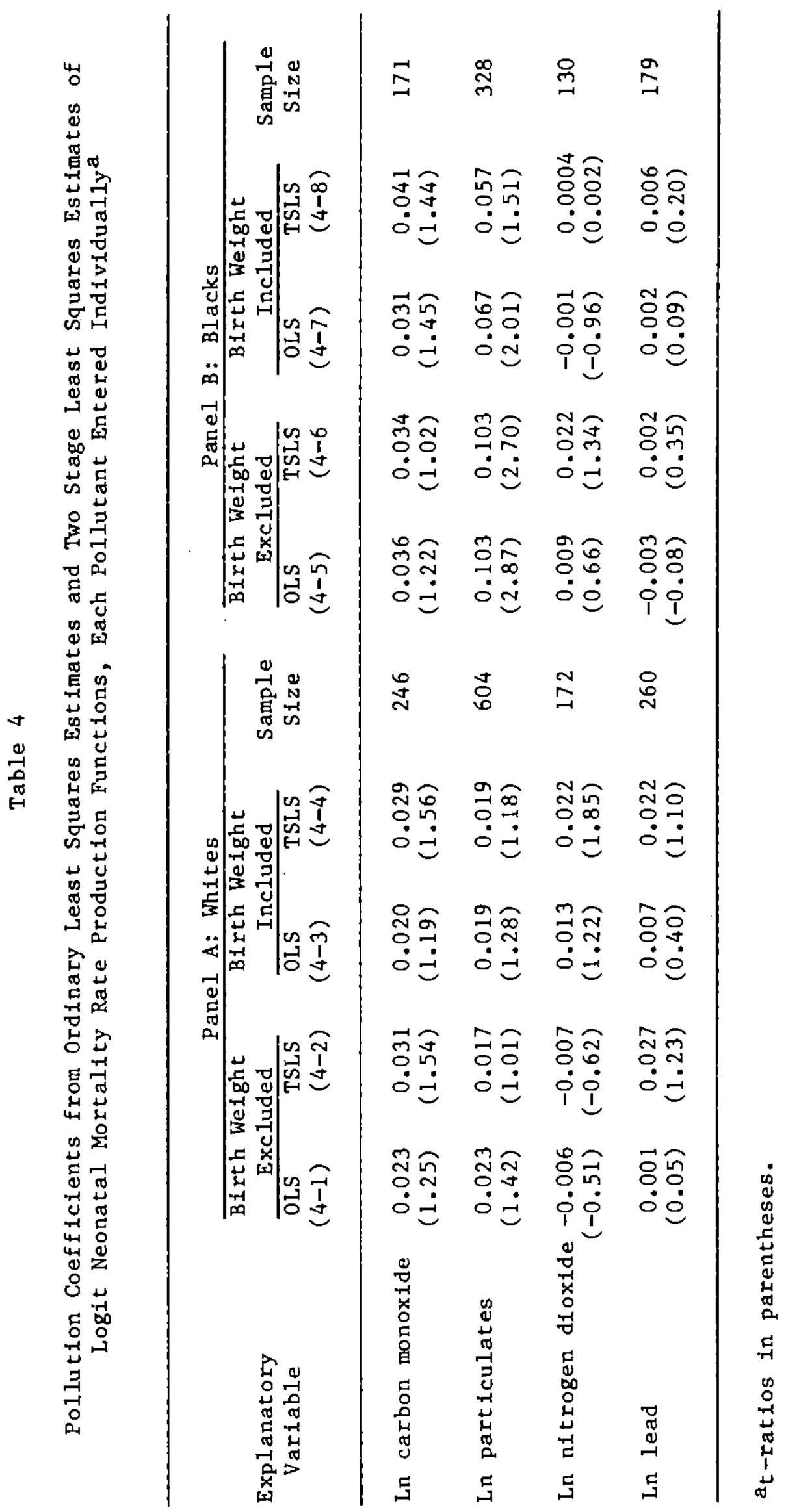


comparison in the five pollutant sample reveals an even greater decline (regressions 2-10 with 2-11 and 3-10 with 3-11). Nevertheless, since the decrease in the magnitude of the sulfur dioxide coefficient is less than fifty percent, the direct effect of this pollutant on neonatal mortality is greater than its indirect effect through low birth weight in every case but one.

In sum, the significance of our results is underscored by model which generated them. By including measures of prenatal care and neonatal care as well as abortion, we have controlled for three health inputs that have a well-documented relationship to neonatal mortality. Moreover, these same inputs have experienced dramatic increases in use during the $1970^{\prime} \mathrm{B}$, a period during which the decline in neonatal mortality accelerated substantially. Stated in Bayesian terms, we posses strong priors for the inclusion of these inputs (Atkinson, Crocker, and Murdock 1985). Furthermore, by examining the impact of pollution on mortality holding the percentage of low-birth weight births constant, we have effectively controlled for the major socioeconomic risk factors (such as births to teenagers and unmarried mothers) that operate through birth weight. In other words, the possibi1ity that the association between sulfur dioxide and early infant deaths represents a spurious relationship due to the omission of other health inputs or risk factors is unlikely.

We conclude this paper by calculating the marginal willingness to pay for declines in sulfur dioxide levels that result in increases in neonatal survival rates. The computations are based on equation (20). Two alternative estimates are presented. In the first the marginal cost of 
improving infant health outcomes is given by the ratio of the price of prenatal care to its marginal product. In the second marginal cost is given by the ratio of the price of neonatal intensive care to its marginal product. For reasons spelled out in Section II and the preceding portion of this section, both computations are based on the TSLS estimates of the quasi-structural production function. The logit coefficients are taken from the sulfur dioxide sample rather than from the five pollutant sample because the former is larger than the latter and because its input coefficients do not differ significantly from those of the full sample.

When prenatal care is used to measure the marginal cost of improving the probability of infant survival, five pieces of information are required to obtain marginal willingness to pay. These are the logit coefficient of environmental quality $\left(\beta_{1}\right)$, the logit coefficient of prenatal care $\left(\beta_{2}\right)$, the specified level of prenatal care (m), the percentage increase in environmental quality divided by 100 (din q) or the percentage decline in pollution ( $-\mathrm{d} \ln z)$ divided by 100 , and the price of prenatal care (p). For whites, $\beta_{1}$ equals .038 , and $\beta_{2}$ equals .516 . For blacks, $\beta_{1}$ equals .049 , and $B_{2}$ equals .162. The specifled value of prenatal care is the mean in the sulfur dioxide sample: .784 in the case of whites and .599 in the case of blacks. Since the marginal-willingness-to-pay formula pertains to small changes, a 10 percent reduction in sulfur dioxide concentrations for each race is considered $(\mathrm{d} \ln \mathrm{q}=.1)$.

If all expectant mothers began prenatal care in the first or second trimester of pregnancy, the price or cost of starting care in the first trimester approximately equals the total cost of three physician visits. 
In turn total cost is given by the direct (money) cost of the visits (the payment to the physician) and the 1ndirect cost (transportation cost plus the sum of travel and walting time multiplied by the opportunity cost of t1me). Most physiclans charge more for an inltial visit than for a followup visit. Fee information provided by the American Medical Association (1984) reveals that obstetriclans/gynecologists, who are the primary suppliers of prenatal care, follow this pricing policy. Since a woman who begins care in the second trimester must have an initial visit, we multiply the price of a follow-up office visit to an obstetrician/gynecologist $\$ 17$ in $1977-$ by three visits to obta1n a direct cost component of $\$ 51.21$ Colle and Grossman (1978) estimate the Indirect cost of a pediatric care visit at $\$ 3$ in 1970 . Th1s is the sum of round-trip travel t1me and walting time multiplled by the hourly wage rate of a mother who works or the potential hourly wage of a mother who does not work. ${ }^{22}$ Based on trends In the hourly wage rate between 1970 and 1977 , the comparable figure for the latter year amounts to $\$ 5$ per visit. Since colle and Grossman 1gnore transportation cost, we expand the 1ndirect cost per visit to $\$ 7$ based on data given by Goldman and Grossman (1978). When mult1plied by three visits, this gives an indirect cost of $\$ 21$. Consequently, the cost of beginning prenatal care in the first trimester rather than in the second tr1mester $18 \$ 72$ in 1977 dollars.

Along the same I1nes, the cost of beginning care in the first trimester rather than the third trimester amounts to the total cost of six follow-up v1s1ts: $\$ 144$ in 1977 dollars. The cost of beginning care in the first trimester rather than obtaining no care at all involves the total cost of an 
Initial visit and eleven follow-up visits. The AMA data indicate that the direct cost of an inftial visit was $\$ 29$ in 1977 . Therefore, cost of this option comes to $\$ 276$.

For each race, the total cost of beginning care in the first trimester 1s defined as a welghted average of the cost of each of the three options. The welght applied to, for example, the first option is the race-specific number of births in which prenatal care began in the second trimester divided by the race-specific number of births with no prenatal care in the first trimester. Th1s gives a total cost of $\$ 94$ for whites and $\$ 100$ for blacks.

In the model outlined in Section II, parents in a given family allocate the same quantity of resources to each birth. Therefore, the figures just given are multiplied by the race-specific total fertility rates in 1977 -1.7 children for white women and 2.3 children for black women. ${ }^{23}$ This ylelds a price of prenatal care equal to $\$ 160$ for whites and $\$ 230$ for blacks. To the extent that prenatal care is financed by private health Insurance and Medicald, the private price or marginal cost is overestimated, although the social marginal cost is not. Under reasonable conditions, this Implies that social marginal willingness on pay exceeds private marginal willingness to pay. ${ }^{24}$ We focus on the former measure. Based on the above data, the social marginal willingness to pay of a typical white woman between the ages of 15 and 44 or her husband comes to $\$ 1$ and the corresponding figure for a typical black woman between the ages of 15 and 44 comes to $\$ 4$. In 1977 there were 34 mfllion white woman in chlldbearing ages in the 677 countries in our data base and 5 million black 
women. Collectively, these women or their familles would have been willing to pay $\$ 54 \mathrm{ml} 111$ on (social marginal willingness to pay). In 1977 dollars for the Improved neonatal survival prospects associated with a 10 percent reduction in sulfur dioxide concentrations.

When neonatal intensive care is used to measure the marginal cost of ralsing the probability of infant survival, the logit coefficients of neonatal intensive care (.147 for whites and .093 for blacks) replace those of prenatal care in the computation of willingness to pay. The specified levels of neonatal intensive care are .646 white patient days per birth and 1.591 black patient days per birth. Budett et al. (1981) report that the cost per case in a Level II or III neonatal intensive care unit was $\$ 8,000$ 1n 1978 and that the average length of stay in such a unit was 13 days. Based on trends in the medical care component of the Consumer Price Index between 1977 and 1978, the cost per patient day in a neonatal intensive care unit was $\$ 568$ in 1977 . Multiplying by the race-specific fertility rates, ore obtains a price of neonatal intensive care of $\$ 966$ for whites and $\$ 1,306$ for blacks. 25

The above data generate much larger values of social marginal w1llingness to pay than those based on prenatal care. To be specific, the soclal marginal willingness to pay of a typical white woman comes to $\$ 16$ and that of a typical black woman comes to $\$ 110$. The collective marginalw11lingness-to-pay-f Igure of $\$ 1.09$ billion is approximately 20 times larger than the $\$ 54$ million sum associated with prenatal care.

The divergence between the two estimates of marginal willingness to pay suggests that the same infant survival probability could be produced at 
lower cost by spending less on neonatal intensive care and more on prenatal care. This does not necessarily mean that pregnant women or their physicians are selecting a non-optimal input mix. Given that neonatal intensive care is financed to a very large extent by private health insurers, the Federal government, and other third parties, the present input mix may well be optimal (cost minimizing) from a private point of view. Of course, it may also be the case that the differential impacts of neonatal care and prenatal care on health outcomes beyond the first month of life justify the current allocation of resources.

We want to emphasize that the main contribution of this paper is not that we have obtained an upper-bound estimate of the benefits of a 10 percent reduction in sulfur dioxide levels of $\$ 1.09$ billion in 1977 dollars and a lower-bound estimate of $\$ 54 \mathrm{mfllion}$. Instead, the main contribution Is that these estimates are obtained from a well specified behavioral model of the production of health, which has been estimated with the appropriate simultaneous equations techniques. They stand in sharp contrast to existing figures that apply extraneous estimates of the value of life or the earnings foregone by premature death to dose-response functions obtained by ordinary least squares. 
FOOTNOTES

${ }^{*}$ Research for th1s paper was supported Cooperative Agreement CR 811041 with the U.S. Environmental Protection Agency. We are Indebted to Linda Edwards, Bart 0stro, Paul Portney, Paul Taubman, and especially George Provenzano for helpful comments and suggestions. We are also indebted to James Cape1, Theodore Johnson, and Roy Paul of PEI Assoctates, Inc. for providing us with alr pollution data from SAROAD. We wish to thank Frank Chaloupka and Nac1 Mocan for research assistance. This paper has not undergone the review accorded official NBER publications; in particular, it has not been submitted for approval by the Board of Directors. Any optlons expressed are those of the authors and not those of EPA or NBER.

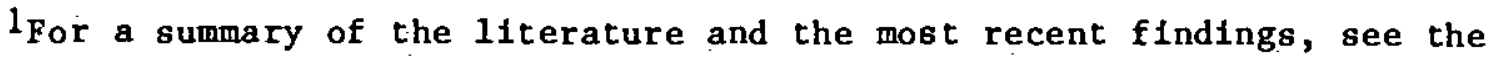
set of articles in the Section I of Bracken (1984).

2 The amount of time worked by the mother during pregnancy and her use of alcohol are excluded from the theoretical model because of lack of data. Rosenzwelg and Schultz (1981, 1982, 1983b) exclude the number of months the mother worked whlle pregnant from thelr flnal estlmates of Infant health production functions because its coefficient was insignificant in preliminary regressions. In a recent report on low birth weight, the Institute of Mediclne (1985) concludes that the association between maternal alcohol use and unfavorable birth outcomes is much less uniform than that between maternal clgarette smoking and these outcomes. Heavy alcohol consumption during pregnancy raises the risk of delfvering a baby with fetal alcohol syndrome. The emplrical evidence is less clear, however, with respect to the effects of moderate or 11ght alcohol use. 
${ }^{3}$ Following the literature on the estimation of dose-response functions by economists and epidemiologists, we treat pollution as exogenous. In a more complete model this variable would have an endogenous component because the amount of exposure to multimedia pollutants and the ingestion of these pollutants depend on decisions with regard to location, diet, and occupation. In addition, at a more aggregate level, state and local governments in areas with high inftial mortality and morbidity rates and high pollution levels may allocate resources to reducing these levels. Note that there exist theoretical and empirical micro-epidemiological studies In which pollution is viewed as endogenous (for example, spengler et al. 1981; Duan 1982), but these studies do not contain estimates of doseresponse functions.

${ }^{4}$ Note that an Increase in e is associated with a more favorable endowment.

50 ther endogenous risk factors in the prematurity production function Include parity and legitimacy status of the birth. These factors are not incorporated into the model because we do not estimate the prematurity production function, as explained below. Clearly, we do not ignore the risk Indicators just cited because they are caused to a large extent by abortion and contraceptive services at the county level.

${ }^{6}$ In the case of cigarette smoking, the detrimental impact of this input is understated in absolute value.

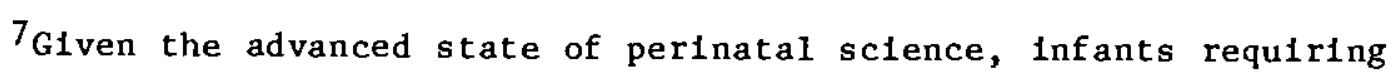
neonatal intensive care services may be Identified prior to birth. Even in this situation low birth weight still causes neonatal intensive care, and 
causality from use to birth weight can be ruled out.

${ }^{8}$ The U.S. Department of Health and Human Services (1980) summarizes numerous studies supporting restriction (2). Restriction (3) is consistent with research of the Institute of Medicine (1985) and Harris (1982). Restriction (4) is supported by Rosenzweig and Schultz (1982, 1983b). In part prematurity is excluded from equation (1) because gestational age is difficult to measure and was not reported on the birth certificates of a number of states during the period of our empirical analysis. If equation (1) is viewed as the one that is obtained by replacing $g$ and $r$ by their determinants, then cigarette smoking must be excluded from the prematurity equation. This is necessary for the quasi-structural mortality and birth weight production functions to satisfy the rank condition. These equations are

$$
\begin{aligned}
1-\pi & =d(n, m, a, c, q, b, x, e) \\
b & =b(m, a, c, q, s, x, e)
\end{aligned}
$$

If $s$ enters the equation for $1-\pi$, the rank condition is satisfied for the birth weight production function but is violated for the mortality production function. Empirical estimates of the above mortality function (not shown) do not differ from the ones presented in Section IV, which exclude x.

${ }^{9}$ Inputs that affect arguments in the utility function besides infant survival cannot be used to compute willingness to pay (Rosen 1981). Therefore, abortion use, family planning use, and maternal cigarette smoking are not employed.

${ }^{10}$ Conceptually, neonatal care has no causal impact on birth weight. 
Therefore, if birth weight is an ideal measure of the endowment, there are two equivalent estimates of the neonatal care coefficient. One is obtained from the structural production function fitted by ordinary least squares. The second is obtained from the quasi-structural production function fitted by two-stage least squares. In the latter case the use of instrumental variables corrects for the correlation between neonatal care use and the disturbance term, while in the former case the inclusion of low birth weight accomplishes the same goal.

11 One county with a population of at least 50,000 persons in 1970 was eliminated from the sample because it was the only such county characterized as an 1solated rural county with no incorporated place with a popu1ation of at least 2,500 persons in 1970. In addition, the District of Columbia was excluded because of difficulty in defining its relevant market area. In particular, many nonresidents use its sophisticated neonatal intensive care hospitals, and these faclilties are not likely to be widely avallable to its relatively large black population. A second reason for excluding the District of Columbia is that Stanley $K$. Henshaw, who estimates resident abortion rates for the Alan Guttmacher Institute, informed us that figures for the District of Columbia are very unreliable.

12 Certain monitors in SAROAD, called source monitors, are located very near to factories and other large sources of industrial pollution. Exposure readings from these monitors are misleading Indicators of the environmental quality of a typical resident of the county in question. Consequently, source monitors were not used in the development of pollution measures at the county level. There are no zeros in the SAROAD data. 
Instead, each pollutant has a minimum detectible level. If readings fall below this point, then the observation is given the value of 1 ts particular minimum detectible level.

13 We experimented with a second algorithm that did not divide counties Into census tracts or minor civil divislons and did not employ population density as a welghting factor. In this algorithm county averages were obtained directly as welghted (by the number of readings) averages of the mon1tor averages. Our results were unaltered. For a more detalled discussion, see Joyce, Grossman, and Goldman (1986).

${ }^{14}$ Two types of averages resulted from the algorithm: an arithmetic average and a logarithmic average (the ant1logarithm of which gives the geometric mean). In addition the logarithmic standard deviation was obtalned. Since pollution measures typlcally have a log-normal distribut1on (for example, Tanner, D'Ottavia, and Gorber 1978), the logarithmic mean plus two standard deviations was used to test and reject the hypothesis that the maximum pollution level is a more 1mportant determinant of neonatal mortality than the mean level. The logarithmic means are employed In the production functions employed in Section IV, but the estimated effects are similar to those obtained with the logarithms of the arithmetic means. The arithmetic means of the pollutants are presented in Table 1 to underscore the close correspondence between the estimated pollution levels In our data base and published figures for the U.S. as a whole during the perlod from 1975 through 1978 (for example, Bureau of the Census 1983, Table 355).

$15_{\text {We }}$ focus on teenage family planning use because neonatal death rates 


$$
F-6
$$

assoclated with births to teenage mothers are substantially higher than births to women beyond the age of 20 (for example, Joyce 1985). Moreover, Forrest (1980) finds that the use of organized family planning services by teenagers has a sizable negative effect on teenage birth rates. It follows that the use of family planning services by teenagers may have a larger impact on neonatal mortality than the use of these services by older women.

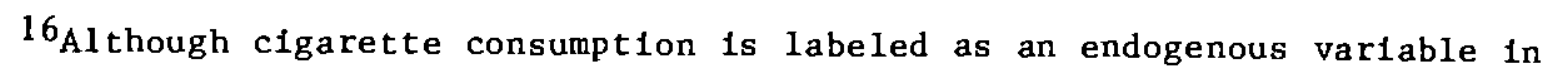
Section IV, it should be noted that the same variable is used in oLS and two-stage estimation procedures.

17 The marginal products of environmental quality and medical care are

$$
\begin{aligned}
& \pi_{q}=\beta_{1} \pi(1-\pi) q^{-1} \\
& \pi_{m}=\beta_{2} \pi(1-\pi)_{m}^{-1} .
\end{aligned}
$$

Hence,

$$
\left(\pi_{q} / \pi_{m}\right)=\left(\beta_{1} / \beta_{2}\right)(m / q) .
$$

18 Put differently, the assumption guarantees that an isoquant between $m$ and $q$ or between $n$ and $q$ us convex to the origin.

${ }^{19}$ In preliminary regressions we experimented with measures pertaining to population density, climate, and the percentage of employed persons who work in manufacturing industries. The inclusion of these regressors had very minor impacts on the coefficients of the pollutants and the health 1nputs. Therefore, they are excluded from the regressions in section IV.

20 The two cases in which the null hypothesis was rejected were the white specification including low birth welght and the black specification excluding low birth weight. The F-statistics were $2.16(6,665 \mathrm{df})$ and $2.79(7,343 \mathrm{df})$, respectively. 
21 The reader is cautioned that obstetricians typically charge pregnant women a flat fee for prenatal visits and the delivery of the child, rather than a fee for each prenatal visit. This suggests that the AMA fee data pertaln to visits to obstetricians/gynecologists for services other than prenatal care. Nevertheless, it is reasonable to assume that the real resource cost of a prenatal care visit is similar to the cost of a gynecological visit. It also is reasonable to assume that an obstetrician will charge a lower flat fee to a woman who begins prenatal care after the first. trimester.

22 The potential wage is estimated from a race-specific regression of the natural logarithm of the hourly wage rate of working mothers on mother's years of formal schooling, mother's years of experience in the labor market, years of experfence squared, and the number of children in the family. Colle and Grossman present separate Indirect cost estimates for whites and blacks, but the two figures are very similar.

${ }^{23}$ The total fertility rate is the number of children a woman would have in her lifetime if, at each year of age, she experienced the birth rate occurring in the specifled year. The total fertility rate of blacks indicated in the text actually pertains to nonwhites.

${ }^{24}$ Price is multiplied by the quantity of prenatal care in the marginal-w1llingness-to-pay formula (20). Therefore, social marginal willingness to pay exceeds private marginal willingness to pay if the price elasticity of demand for prenatal care is less than one in absolute value. While there are no estimates of this parameter, Ghez and Grossman (1980) summarize a number of studies in which the price elasticlty of demand for 


$$
F-8
$$

physician visits by adults or children is less than one. Note that social marginal willingness to pay is not necessarily overstated if social marginal cost is multiplied by the observed quantity of prenatal care in equation (20). This depends on whether the observed quantity exceeds, equals, or falls short of the socially optimal quantity. For a detailed discussion of the latter concept, see Ghez and Grossman (1980).

${ }^{25}$ The Indirect cost component of neonatal intensive care is ignored. To be sure, a mother with an infant in a neonatal intensive care unit will spend much more time in the hospital than otherwise. But she probably would not have returned to her usual activities even if her infant had not been hospitalized. It should be noted, however, that the psychic cost of the hospitalization clearly is substantial. 


\section{References}

American Medical Association. Socloeconomic Characteristics of Medical

Practice. Chicago: American Medical Association, 1984.

Atkinson, Scott E.; Crocker, Thomas D.; and Murdock, Robert 0 .

"Have Priors in Aggregate Afr Pollution Epidemiology Dictated

Posteriors?" Journal of Urban Economics, 17 (1985).

Bracken, Michael B., ed. Perinatal Epldemlology. New York: Oxford University Press, 1984.

Budett1, Peter, et al. "Costs and Effectiveness of Neonatal Intensive

Care." In The Implications of Cost-Effectiveness Analys is of Medical

Technology: Office of Technology Assessment, U.S. Congress.

Washington, D.C.: U.S. Government Printing office, 1981.

Bureau of the Census, U.S. Department of Commerce. Statistical Abstract of

the United States. Washington, D.C.: U.S. Government Printing office, 1983.

Chapple, Mike, and Lave, Lester B. "The Healths Effects of Alr Pollution:

A Reanalysis." Journal of Urban Economics, 12 (November 1982).

Colle, Ann D., and Grossman, Michael. "Determinants of Pedlatric Care

Ut111zation." Journal of Human Resources, 13, Supplement (1978).

Corman, Hope, and Grossman, Michael. "Determinants of Neonatal Mortality

Rates 1n the U.S.: A Reduced Form Model." Journal of Health Economics,

4, No. 3 (September 1985 ).

Corman Hope; Joyce, Theodore J.; and Grossman, Michael. "B1rth Outcome

Production Functions in the U.S." National Bureau of Economic Research

Work1ng Paper No. 1729, October 1985. 


$$
\mathrm{R}-2
$$

Crocker, Thomas D., et al. "Methods Development for Assessing Air Pollution Control Benefits, Volume I: Experiments in the Economics of Air Pollution Epidem1ology." EPA Grant NO. R805059010, February 1979.

Duan, Na1hua. "Models for Human Exposure to Air Pollut1on." Environment Internationa1, 8 (1982).

Edwards, Linda N., and Grossman, Michael. "The Relat1onship between Ch1ldren's Health and Intellectual Development." In Health: What is 1t Worth?, edited by Selma J. Mushkin and Dav1d W. Dunlop. Elmsford, New York: Pergamon Press, 1979.

Forrest, Jacqueline D. "Exploration of the Effects of Organized Fam1ly Plann1ng Programs in the Un1ted States on Adolescent Fertil1ty." Final Report, Contract No. NOl-HD-82844 from the National Center of Child Health and Human Development to the Alan Guttmacher Institute, October 1980.

Freeman, A. Myrick III. The Benefits of Environmental Improvement: Theory and Practice. Baltimore, Maryland: Johns Hopkins Un1versity Press, 1979.

Gerking, Shelby D. "An Economic Analys1s of Air Pollution and Health: The Case of St. Louis." Final Report, EPA Ass1stance Agreement CR808893010, March 1983.

Gerking, S., and Schulze, W. "What Do We Know About Benef1ts at Reduced Mortality from Afr Pollution?" Amer1can Economic Review, 71, No. 2 (May 1981).

Ghez, G11bert R., and Grossman, Michael. "Prevent1ve Care, Care for 


$$
R-3
$$

Children, and National Health Insurance." In National Health Insurance: What Now, What Later, What Never?, edited by Mark V. Pauly. Washington, D.C.: American Enterprise Institute, 1980. Goldman, Fred, and Grossman, Michael. "The Demand for Pediatric Care: An Hedonic Approach." Journal of Political Economy, 86, No. 2, Part I (Apri1 1978).

Grossman, Michael, and Jacobowitz, Steven. "Varlations in Infant Mortality Rates Among Counties of the United States: The Roles of Public Policles and Programs." Demography, 18, No. 4 (November 1981).

Harrington, Winston, and Portney, Paul R. "Valuing the Benefit of Improved Human Health." Unpublished paper, 1983.

Harris, Jeffrey E. "Prenatal Medical Care and Infant Mortality." In Economic Aspects of Health, edited by Victor R. Fuchs. Chicago: University of Chicago Press for the National Bureau of Economic Research, 1982.

Joyce, Theodore J.; Grossman, Michae1; and Goldman, Fred. "Air Pollution and Infant Health Outcomes." In "Health Econometric Methods for Multimedia Pollutants." Final Report, EPA Cooperative Agreement CR811041, April 1986.

Joyce, Theodore J. "The Impact of Induced Abortion on Birth Outcomes in the U.S." National Bureau of Economic Research Working Paper No. 1757, October 1985.

Lave, Lester B., and Seskin, Eugene P. Alr Pollution and Human Health. Baltimore, Maryland: Johns Hopkins University Press, 1977. Lave, Lester B., and Seskin, Eugene. "Air Pollution and Human Health.“ 


$$
R-4
$$

Science, 169 (August 1970).

Lave, Lester B., and Seskin, Eugene P. "An Analysis of the Association Between U.S. Mortality and Air Pollution." Journal of the American Statistical Association, 68, No. 342 (June 1973).

Lewit, Eugene M. "The Demand for Prenatal Care and the Production of Healthy Infants." In Volume III of the Annual Series of Research in Human Capital and Development, edited by Ismall Sirageldin, David Salkever, and Alan Sorkin. Greenwich, Connecticut: JAI Press, Inc., 1983.

Maddala, G.S. Limited-Dependent and Qualitative Variables in Econometrics. Cambridge, England: Cambridge University Press, 1983. Mendelsohn, Robert, and Orcutt, Guy. "An Empirical Analysis of Afr Pollution Dose-Response Curves." Journal of Environmental Economics and Management, vol. 6 (1979).

Nakamura, A., and Nakamura, M. "On the Relationship Among Several Specification Error Tests Presented by Durbin, Wu and Hansman." Econometrica, Vol. 69, No. 6 (November 1981). Rosen, Sherwin. "Valuing Health Risk." American Economic Review, 71, No. 2 (May 1981).

Rosenzweig, Mark R., and Schultz, T. Paul. "The Behavior of Mothers as Inputs to Child Health: The Determinants of Birth Welght, Gestation, and Rate of Fetal Growth." In Economic Aspects of Health, edited by Victor R. Fuchs. Chicago: University of Chicago Press for the National Bureau of Economic Research, 1982. Rosenzwelg, Mark R., and Schultz, T. Paul. "Consumer Demand and Household 
Production: The Relationshlp Between Fertilfty and Child Mortalfty." American Economlc Review, 73, No. 2 (May 1983a).

Rosenzwelg, Mark R., and Schultz, T. Paul. "Education and Household Production of Child Health." Proceedings of the American Statistical Assoctation, Soctal Statistics Section. Washington, D.C.: American Statistical Assoclation, 1981.

Rosenzwelg, Mark R., and Schultz, T. Paul. "Estlmating a Household Production Function: Heterogenefty, the Demand for Health Inputs, and their Effects on Blrth Welght." Journal of Political Economy, 91 No. 5 (October 1983b).

Shakotko, Robert A., Edwards, LInda N.; and Grossman, Michael. "An Exploration of the Dynamic Relationshlp between Health and Cognitive Development in Adolescence." In Contributions to Economic Analysis: Health, Economics, and Health Economlcs, edited by Jaques van der Gaag and Mark Perlman. Amsterdam: North-Holland Publishlng Company, 1981. Spengler, John D., et al. "Personal Exposures to Resplrable Partfculates: A Tale of Two Cltles--Kingston, and Harriman, Tennessee." Presented at the International Sympostum on Indoor Afr Pollution, Health, and Energy Conservation, Amherst, Massachusetts, October, 1981.

Taffel, Selma. Factors Associated with Low Birth Welght, Unted States, 1976. U.S. Department of Health, Education, and Welfare, Publlc Health Service, National Center for Health Statistics, Vital and Health Statist1cs, Series 21, No. 37 (Apr11 1980).

Tanner, R.L.; D'Ottavis, T.; and Gorber, R. "Determination of Atmospheric Gaseous and Partlculate Sulfur Compounds." In Sulfur Environment: 


$$
R-6
$$

Part I, The Atmospheric Cycle, edited by J. O. Nriagu. New York: John Wiley and Sons, 1978.

U.S. Department of Health and Human Services. The Health Consequences of Smoking for Women: A Report of the Surgeon General. Washington, D.C.: U.S. Government Printing office, 1980.

Wu, D. "Alternative Tests of Independence Between Stochastic Regressors and Disturbances." Econometrica, Vol. 41, No. 9 (July 1973). 